\title{
Fostering PT-PTA Student Relationships, Pilot Study
}

Kelly Hawthorne

Saint Louis University, hawthokd@slu.edu

Christina Cohoon

St. Louis Community College, ccohoon1@stlcc.edu

Eric Chambers

St. Louis Community College, echambers22@stlcc.edu

Follow this and additional works at: https://nsuworks.nova.edu/ijahsp

Part of the Medicine and Health Sciences Commons

\section{Recommended Citation}

Hawthorne K, Cohoon C, Chambers E. Fostering PT-PTA Student Relationships, Pilot Study. The Internet Journal of Allied Health Sciences and Practice. 2018 Jan 01;16(1), Article 4.

This Manuscript is brought to you for free and open access by the College of Health Care Sciences at NSUWorks. It has been accepted for inclusion in Internet Journal of Allied Health Sciences and Practice by an authorized editor of NSUWorks. For more information, please contact nsuworks@nova.edu. 


\title{
Fostering PT-PTA Student Relationships, Pilot Study
}

\begin{abstract}
Purpose: The purpose of this study was to assess physical therapist (PT) and physical therapist assistant (PTA) students' attitudes toward working in a team, direction and supervision, preparation for effective communication, and respect for and the value of physical therapist/physical therapist assistant (PT/PTA) teams following an interactive classroom session via a brief online questionnaire.
\end{abstract}

Methods: PT students in the second year of their doctor of physical therapy graduate studies in St Louis, MO and PTA students in the second year of their associate's degree program in St Louis, MO were involved. A questionnaire was completed prior to and after attending an interactive classroom session. The interactive session included four stations; curriculum and education, communication and documentation, PT/PTA teamwork scenarios in different practice settings, and social interaction. The questionnaire consisted of six questions asking students to indicate their level of agreement or disagreement.

Results: Attendance status at the interactive session was related to student responses on the questionnaire for both PT and PTA students. Among PTA students, responses on three of six questionnaire items were found not to be independent of attendance status. PTA students indicated they felt more prepared for PT/PTA communication, had more respect for the similarities in roles of PTs and PTAs, and felt more strongly that effective PT/PTA teams were essential to optimal patient care. Among the PT student population, the only questionnaire item found to be independent of interactive session attendance status was the belief in effective PT/PTA teams. Generally, students' responses tended to be more positive after attending the interactive session, with "Strongly agree" responses increasing by as much as 24 percent on some questionnaire items. Increases in weighted means for PTA students were not found to be statistically significant; however, among PT students these increases were significant across three questionnaire items.

Conclusions: The findings suggest that both PT and PTA students experienced increased comfort with the idea of working as part of a PT/PTA team after the interactive event where communication was the focus. The affective behavior of "comfort" in working as part of a PT/PTA team increased in our study among both PT and PTA students. The interactive session was easy to implement and had no cost associated with it. Follow-up study or methodologies could provide more robust results to further support these findings. This activity could also be replicated across healthcare professions that utilize professional and paraprofessional assistant relationships.

\section{Author Bio(s)}

Kelly Hawthorne PT, DPT, GCS, CEEAA, is an Assistant Professor in the Program in Physical Therapy at Saint Louis University in St. Louis, MO. She is a physical therapist in the state of Missouri.

Christina Cohoon PT, DPT, OCS, is an Associate Professor in the Physical Therapist Assistant Program at St. Louis Community College in St. Louis, MO. She is a physical therapist in the state of Missouri.

Eric Chambers BA, MPA, is a Senior Research Associate in the Department of Institutional Research and Planning at St. Louis Community College in St. Louis, MO.

\section{Acknowledgements}

We would like to thank Ms. Julie High MS, PT, Program Coordinator of the Physical Therapist Assistant Program at St. Louis Community College, and Rebecca Helbling, Professor and Reference Librarian at St. Louis Community College for their assistance.

This manuscript is available in Internet Journal of Allied Health Sciences and Practice: https://nsuworks.nova.edu/ijahsp/vol16/iss1/4 


\title{
IJAHSP \\ The Internet Joưnal of Allied Health Sciences and Practice
}

Dedicated to allied health professional practice and education

Vol. 16 No. 1 ISSN 1540-580X

\section{Fostering PT-PTA Student Relationships, Pilot Study}

\author{
Kelly Hawthorne, PT, DPT, GCS, CEEAA ${ }^{1}$ \\ Christina Cohoon, PT, DPT, OCS 2 \\ Eric Chambers, BA, MPA ${ }^{2}$
}

1. Saint Louis University

2. Saint Louis Community College

United States

\begin{abstract}
Purpose: The purpose of this study was to assess physical therapist (PT) and physical therapist assistant (PTA) students' attitudes toward working in a team, direction and supervision, preparation for effective communication, and respect for and the value of physical therapist/physical therapist assistant (PT/PTA) teams following an interactive classroom session via a brief online questionnaire .Methods: PT students in the second year of their doctor of physical therapy graduate studies in St Louis, MO and PTA students in the second year of their associate's degree program in St Louis, MO were involved. A questionnaire was completed prior to and after attending an interactive classroom session. The interactive session included four stations; curriculum and education, communication and documentation, PT/PTA teamwork scenarios in different practice settings, and social interaction. The questionnaire consisted of six questions asking students to indicate their level of agreement or disagreement. Results: Attendance status at the interactive session was related to student responses on the questionnaire for both PT and PTA students. Among PTA students, responses on three of six questionnaire items were found not to be independent of attendance status. PTA students indicated they felt more prepared for PT/PTA communication, had more respect for the similarities in roles of PTs and PTAs, and felt more strongly that effective PT/PTA teams were essential to optimal patient care. Among the PT student population, the only questionnaire item found to be independent of interactive session attendance status was the belief in effective PT/PTA teams. Generally, students' responses tended to be more positive after attending the interactive session, with "Strongly agree" responses increasing by as much as 24 percent on some questionnaire items. Increases in weighted means for PTA students were not found to be statistically significant; however, among PT students these increases were significant across three questionnaire items. Conclusions: The findings suggest that both PT and PTA students experienced increased comfort with the idea of working as part of a PT/PTA team after the interactive event where communication was the focus. The affective behavior of "comfort" in working as part of a PT/PTA team increased in our study among both PT and PTA students. The interactive session was easy to implement and had no cost associated with it. Follow-up study or methodologies could provide more robust results to further support these findings. This activity could also be replicated across healthcare professions that utilize professional and paraprofessional assistant relationships.
\end{abstract}

\section{INTRODUCTION}

Many healthcare professionals have paraprofessional assistants that work under the direction and supervision of the professional. Although these assistants are part of the same profession, belong to the same national professional organizations and work together as teams in healthcare settings, their formal educational training and roles in practice are quite different, and not always very well understood. Jung et al. performed a study pairing Occupational Therapist (OT) and Occupational therapist Assistant (OTA) in clinical practice resulting in themes of developing the relationship, understanding roles, and recognizing environmental influences in learning. ${ }^{1}$ Jung et al. states "Communication is critical in the development of a collaborative relationship between the OT and the OTA". ${ }^{1}$ Similarly, the physical therapy profession relies on the same relationships and therefore exploring these themes is essential in the Physical therapist/Physical therapists Assistant (PT/PTA) relationship. In 2013, a study focused on perceptions of the PT/PTA relationship and communication was determined to be the key to role delineation and effective PT/PTA collaboration. ${ }^{2}$

(C) The Internet Journal of Allied Health Sciences and Practice, 2018 
Physical therapy education programs are clinical doctorate level programs typically requiring three years of graduate study beyond completion of a bachelor's degree. Physical therapy assistant education programs are typically two year associates degree programs with the majority of accredited programs in community colleges. There are accreditation requirements for both PT and PTA programs for educational learning experiences, however; typically, there is little interaction between PT and PTA students before graduation.

There is a paucity of intraprofessional literature on the topic of PT/PTA interactions in physical therapy education. In the mid-90s, a pair of studies reported that although practice guidelines were well understood there was continued misunderstanding by both PTs and PTAs regarding the role of performing specific data collection techniques in the clinical setting.,3,4 In 2004, Cavallo and Richter concluded that "PT students maintain an overall positive attitude toward PTAs before and after full-time clinical internships". ${ }^{5}$ This finding is important to physical therapy practice because a positive practice environment is reliant upon a positive PT/PTA working relationship. In 2006, an instructional model to educate PT students in the classroom about PTAs was presented in the literature. ${ }^{6}$ Here, the instruction consisted of three classroom sessions and an interactive team based problem solving session. This model was deemed effective in teaching PT students about the role of the PTA, and fostering PT/PTA relationships. ${ }^{6}$ In 2010, a case report regarding perceptions of PT and PTA students of a shared clinical experience was published. ${ }^{7}$ It was found that following this clinical experience, the students' collaboration and delegation skills improved. ${ }^{7}$

In contrast, there have been many studies that describe different learning methods used in interprofessional education (IPE) including patient simulation, patient care experiences, and multi-component IPE activities. ${ }^{8-12}$ Computer based virtual patients have been used for healthcare student collaboration. Through computer based patient care, students from a variety of disciplines were able to develop comprehensive treatment plans while reflecting on the value of interprofessional collaboration. ${ }^{8}$ Nursing students and other healthcare professional students, using models for simulation (SIM), found that patient errors were reduced and safety was improved. ${ }^{9}$ Pharmacy, nursing, physician assistant, and physical therapy (PT) students from four different educational programs held a community fall prevention event, led by faculty, where students recognized the value of working together as an interprofessional (IP) team..$^{10} \mathrm{~A}$ large longitudinal study from Finland focused on students' attitudes and perceptions of IPE over a six year period from across ten healthcare professions. ${ }^{11}$ They found sustained high value of communication, trust, and respect for one another's roles utilizing a multi-component approach to IPE. ${ }^{11}$ Another longitudinal study of 13 professions provided care to patients in interprofessional teams. One poignant finding from this study was the importance of including the patient in the IP model following the experience. ${ }^{12}$

The purpose of this study was to assess PT and PTA students' attitudes toward working in a team, direction and supervision, preparation for effective communication, and respect for and the value of PT/PTA teams following an interactive classroom session via a brief online questionnaire. The hypothesis was that students would feel more positive and comfortable about their own professional communication and teamwork roles and responsibilities following an informal interactive experience.

\section{METHODS}

PT students from Saint Louis University in the second year of their graduate studies and PTA students in the second year of their associate's degree program from St. Louis Community College (STLCC) were involved. These students will graduate from their respective educational programs around the same time, had introductory didactic classroom information about the other profession, but have not yet interacted face to face. Both PT and PTA students participated in this interactive classroom session as part of their required educational coursework. Recruitment in this study involved emailing students a link to a questionnaire with a request for completion. There were no points assigned upon completion of the questionnaire in either program, and completion was voluntary with no consequences for not completing it. No incentives were offered and no payments were made to subjects. The study was approved by Saint Louis University's Institutional Review Board and reviewed by the Human Subjects Review Board at St. Louis Community College.

The interactive classroom session was held at the STLCC in the PTA Program classroom. A questionnaire was completed two days prior to and immediately after attending the interactive classroom session. Questionnaire items were developed in alignment with course objectives for both programs after a review of the literature indicating critical components of intraprofessional and interprofessional practice. Preliminary questionnaire items were reviewed by a peer educator with knowledge of both PT and PTA education and practice. Feedback was incorporated into the final draft of the questions. Student responses on the questionnaire were anonymous. The questionnaire consisted of six questions where students were asked to indicate their level of agreement or disagreement. The responses were assigned numerical values from 1-strongly disagree to 5 -strongly agree. Student responses prior to the interactive session were compared to responses following the session. Given the short time period involved between completion of the survey and the interactive session, any significant changes from pre-test to post-test should be primarily attributable to the interactive classroom session rather than other potential contributing factors such as additional coursework.

(c) The Internet Journal of Allied Health Sciences and Practice, 2018 
Survey Monkey was utilized to conduct the survey and the data was stored at STLCC by the department of Institutional Research and Planning. ${ }^{13}$ Survey Monkey was selected as it is the current survey tool used by STLCC, and it also provided a number of benefits to users including multiple collection methods, some limited automated statistical analysis tools, and automated report generation. The results were anonymous and collected electronically. No identifying information about the student was collected. The type of student (PT vs PTA) was recorded for comparison of results.

The intervention was an interactive session included four stations; curriculum and education, communication and documentation, PT/PTA teamwork scenarios in different practice settings, and social interaction. Minimal faculty preparation was required. The PT faculty introduced the learning objectives for the session and encouraged the PT students to interact following the PTA students' leads. The PTA faculty also introduced the learning objectives for the session, and provided minimal guidance for the PTA students to lead each station. With the intent of keeping the interactive session a student to student open forum, no formal questions were posed within the stations, and slight variability inevitable did occur at each station. PTA students introduced each station, and then both groups shared information about their education, skills, and background, and answered questions. PT students rotated to a different station every ten to fifteen minutes, completing all four stations. Station one, curriculum and education, focused on the didactic portion of each program. Here, a curricular overview, textbooks, practical exam checklists, and even course instructors who were familiar to both groups of students, were shared and discussed. Station two, communication and documentation, involved the students viewing a video of someone walking. The students then discussed how they would communicate these gait deviations to each other in a clinical setting via documentation. In station three, PT/PTA teamwork scenarios in different practice settings, students shared knowledge of specific clinical practices regarding delegation and supervision unique to that setting (Outpatient, Inpatient, Skilled Nursing Facility). Discussion included things like when an in person supervisory meeting was required, how often documentation reviews were expected, and how these practices would be best communicated. Finally, station four was the least structured station focusing on students' social interactions. Here students shared personal information such as previous degrees earned, family life, work history, personal and professional goals, and hobbies, with the intent to allow students to learn more about each other on a personal level to enhance their potential future professional relationships.

In order to assess whether students' attitudes changed after participating in the interactive sessions a number of quantitative analyses were conducted. All analysis was conducted using SPSS Statistics. A chi-square test was performed as a preliminary test in order to assess whether any of the questionnaire items were independent of interactive session attendance status. In addition, response proportions were compared to identify where differences occur, if at all. The comparison of response proportions calculates a test statistic based on response counts and the standard error with a confidence level of $95 \%$. Weighted response means were then analyzed for statistically significant differences using an independent samples t-test. The responses from prior to the session and following the session were treated as independent samples due to collection methodology (i.e., anonymity) and a lack of additional demographic or other information that would allow for matched-pairs analysis. Changes to the collection of data moving forward could allow for paired sample or matched-pairs analysis, which would provide greater power compared to treating the groups as independent.

In addition to the primary goal of identifying changes in outlook resulting from attending the interactive session, the two student groups were compared to explore any differences between PT and PTA students using the same analysis methods as those mentioned above.

\section{RESULTS}

All PT and PTA students attended the event and were invited to respond to the questionnaire. There were a total of 84 responses were collected from PTA students, 43 prior to the interactive session and 41 after. Among PT students, there were 188 responses before the interactive session and 180 post-event responses for a total of 368 . The response counts are combined across multiple semesters; however, the event and questionnaire were unchanged. Table 1 below presents total response counts by student type and time of response.

Table 1. Response Rates

\begin{tabular}{|l|c|c|c|c|}
\hline & \multicolumn{2}{|c|}{ PT Students } & \multicolumn{2}{c|}{ PTA Students } \\
\hline & Pre-Session & Post-Session & Pre-Session & Post-Session \\
\hline Response rates & $98.4 \%$ & $94.2 \%$ & $100 \%$ & $95.3 \%$ \\
\hline
\end{tabular}

Chi-square tests of independence were conducted on each group of students as exploratory analysis to determine whether questionnaire items were related with interactive session attendance status. The results of the chi-square analysis showed that among PTA students, three of the six questionnaire items were not independent of attendance status at the interactive session. The survey items identified as being related to attendance status for PTA students were: "I am prepared to communicate effectively

(C) The Internet Journal of Allied Health Sciences and Practice, 2018 
as part of a PT-PTA team," "I respect the similarities in roles of PTs and PTAs," and "I believe effective PT-PTA teams are essential to providing optimal patient care." Among PT students, all but one survey item was found to be related to attendance status. "I believe effective PT-PTA teams are essential to providing optimal patient care" was the sole item, among PT students, found to be independent of attendance status. Table 2, below, contains the chi-square statistic between pre-session and post-session for each group of students.

\begin{tabular}{|l|c|c|c|c|}
\hline \multicolumn{1}{|c|}{ Questionnaire Item } & \multicolumn{2}{c|}{ PT Students } & \multicolumn{2}{c|}{ PTA Students } \\
\hline \multicolumn{1}{|c|}{ Pearson chi-square } & $p$ & Pearson chi-square & \multicolumn{1}{c|}{$p$} \\
\hline I am comfortable working as part of a PT-PTA team. & 32.504 & $.000^{*}$ & 6.113 & .106 \\
\hline $\begin{array}{l}\text { I am prepared for the direction and supervision } \\
\text { involved in working as part of a PT-PTA team. }\end{array}$ & 23.849 & $.000^{*}$ & 7.644 & .054 \\
\hline $\begin{array}{l}\text { I am prepared to communicate effectively as part of } \\
\text { a PT-PTA team. }\end{array}$ & 27.275 & $.000^{*}$ & 9.653 & $.047^{*}$ \\
\hline I respect the similarities in roles of PTs and PTAs. & 19.430 & $.001^{*}$ & 8.550 & $.036^{*}$ \\
\hline I respect the differences in roles of PTs and PTAs. & 17.225 & $.001^{*}$ & 5.422 & .143 \\
\hline $\begin{array}{l}\text { I believe effective PT-PTA teams are essential to } \\
\text { providing optimal patient care. }\end{array}$ & 7.443 & .059 & 8.457 & $.037^{*}$ \\
\hline
\end{tabular}

${ }^{*}$ Denotes statistical significance $(\alpha=.05)$

Further analysis was conducted to identify where differences on questionnaire items before and after the interactive session may be present. Response proportions were compared by calculating a test statistic based on response counts and the standard error. Results of this analysis, presented in Tables 3 and 4, show that where relationships exist, student sentiments tended to improve post-session compared to before the event.

Table 3. PTA Students' Response Percentages

\begin{tabular}{|l|c|c|c|c|c|c|c|c|c|c|}
\hline & \multicolumn{2}{|c|}{ Strongly disagree } & \multicolumn{2}{c|}{ Disagree } & \multicolumn{2}{c|}{ Neutral } & \multicolumn{2}{c|}{ Agree } & \multicolumn{2}{c|}{ Strongly agree } \\
\hline & Pre & Post & Pre & Post & Pre & Post & Pre & Post & Pre & Post \\
\hline Item 1 & $0 \%$ & $4.9 \%$ & $0 \%$ & $0 \%$ & $11.6 \%$ & $2.4 \%$ & $34.9 \%$ & $24.4 \%$ & $53.5 \%$ & $68.3 \%$ \\
\hline Item 2 & $0 \%$ & $4.9 \%$ & $0 \%$ & $0 \%$ & $18.6 \%$ & $4.9 \%$ & $32.6 \%$ & $22 \%$ & $48.8 \%$ & $68.3 \%$ \\
\hline Item 3 & $0 \%$ & $4.9 \%$ & $2.3 \%$ & $0 \%$ & $7 \%$ & $2.4 \%$ & $39.5 \%^{*}$ & $17.1 \%^{*}$ & $51.2 \%^{*}$ & $75.6 \%^{*}$ \\
\hline Item 4 & $0 \%$ & $4.9 \%$ & $0 \%$ & $0 \%$ & $2.3 \%$ & $2.4 \%$ & $37.2 \%^{*}$ & $12.2 \%^{*}$ & $60.5 \%{ }^{*}$ & $80.5 \%^{*}$ \\
\hline Item 5 & $0 \%$ & $4.9 \%$ & $0 \%$ & $0 \%$ & $2.3 \%$ & $2.4 \%$ & $32.6 \%$ & $14.6 \%$ & $65.1 \%$ & $78 \%$ \\
\hline Item 6 & $0 \%$ & $4.9 \%$ & $0 \%$ & $2.4 \%$ & $0 \%$ & $0 \%$ & $18.6 \%^{*}$ & $2.4 \%^{*}$ & $81.4 \%$ & $90.2 \%$ \\
\hline
\end{tabular}

${ }^{*}$ Denotes statistical significance between pre-session and post-session rates $(a=.05)$

Table 4. PT Students' Response Percentages

\begin{tabular}{|l|c|c|c|c|c|c|c|c|c|c|}
\hline & \multicolumn{2}{|c|}{ Strongly disagree } & \multicolumn{2}{c|}{ Disagree } & \multicolumn{2}{c|}{ Neutral } & \multicolumn{2}{c|}{ Agree } & \multicolumn{2}{c|}{ Strongly agree } \\
\hline & Pre & Post & Pre & Post & Pre & Post & Pre & Post & Pre & Post \\
\hline Item 1 & $0.5 \%$ & $2.2 \%$ & $4.3 \%^{*}$ & $0 \%^{*}$ & $19.7 \%^{*}$ & $3.9 \%^{*}$ & $31.9 \%$ & $38.3 \%$ & $43.6 \%^{*}$ & $55.6 \%^{*}$ \\
\hline Item 2 & $0 \%$ & $2.2 \%$ & $11.7 \%^{*}$ & $3.9 \%^{*}$ & $22.3 \%^{*}$ & $10 \%^{*}$ & $35.1 \%$ & $44.4 \%$ & $30.9 \%$ & $39.4 \%$ \\
\hline Item 3 & $0 \%$ & $2.2 \%$ & $3.2 \%^{*}$ & $0 \%^{*}$ & $13.3 \%^{*}$ & $6.1 \%^{*}$ & $47.3 \%^{*}$ & $34.4 \%^{*}$ & $36.2 \%^{*}$ & $57.2 \%^{*}$ \\
\hline Item 4 & $0 \%$ & $2.2 \%$ & $0 \%$ & $0.6 \%$ & $4.8 \%^{*}$ & $0.6 \%^{*}$ & $38.8 \%^{*}$ & $25.6 \%^{*}$ & $56.4 \%^{*}$ & $71.1 \%^{*}$ \\
\hline Item 5 & $0 \%$ & $2.2 \%$ & $0 \%$ & $0 \%$ & $4.8 \%^{*}$ & $0.6 \%^{*}$ & $39.4 \%^{*}$ & $27.2 \%^{*}$ & $55.9 \%^{*}$ & $70 \%^{*}$ \\
\hline Item 6 & $0 \%$ & $2.2 \%$ & $0 \%$ & $0 \%$ & $2 \%$ & $2 \%$ & $30.3 \%$ & $21.7 \%$ & $68.1 \%$ & $73.9 \%$ \\
\hline
\end{tabular}

* Denotes statistical significance between pre-session and post-session rates $(\alpha=.05)$ 
As shown in the tables above, students' outlook, already generally positive prior to the interactive session, tended to improve after attending the session. Among PTA students, the percent of respondents who indicated "Strongly agree" on item 3 ("I am prepared to communicate effectively as part of a PT-PTA team") increased by over 24 percent. This held true for PT students as well. Among PT students on Items 1-3, for example, the percentage of students that responded "Disagree" declined by 4.3 percent, 7.8 percent, and 3.2 percent, respectively. Conversely, the percentage of PT students responding "Strongly agree" after attending the event increased significantly on four of the six items. Items 1, 3, 4, and 5 saw increases of 12 percent, 21 percent, 15 percent, and 14 percent, respectively, on the "Strongly agree" response.

The response categories were assigned numerical values from 1 ("Strongly disagree") to 5 ("Strongly agree"). Weighted means were calculated by multiplying the weight of a given response by the number of responses for that option then dividing by the total number of responses. The weighted means of each questionnaire item were then compared between pre-session and post-session for each student group using a t-test. The PTA students attending the interactive session tended to have slightly more positive outlook on the items compared to before the event, however, the differences found were not statistically significant. Similarly, the PT students generally had higher weighted means after the event than before the event. Among the PT students, the first three questionnaire items were found to be statistically significant. The lack of significance among the PTA students may be, in part, due to the relatively smaller number of students as a larger $\mathrm{n}$ will typically provide greater statistical power.

Table 5. Comparison of Weighted Means

\begin{tabular}{|c|c|c|c|c|c|c|c|c|}
\hline & \multicolumn{9}{|c|}{ PTA Students } & \multicolumn{4}{c|}{ PT Students } \\
\hline & Pre & Post & $\mathbf{t}$ & $\mathbf{p}$ & Pre & Post & $\mathbf{t}$ & $\mathbf{p}$ \\
\hline Item 1 & 4.42 & 4.51 & 0.52 & 0.61 & 4.14 & 4.45 & 3.54 & $0.00^{*}$ \\
\hline Item 2 & 4.30 & 4.49 & 0.97 & 0.34 & 3.85 & 4.15 & 3.01 & $0.00^{*}$ \\
\hline Item 3 & 4.39 & 4.59 & 1.03 & 0.30 & 4.16 & 4.44 & 3.41 & $0.00^{*}$ \\
\hline Item 4 & 4.58 & 4.63 & 0.32 & 0.75 & 4.52 & 4.63 & 1.61 & 0.11 \\
\hline Item 5 & 4.63 & 4.61 & -0.11 & 0.91 & 4.51 & 4.63 & 1.71 & 0.09 \\
\hline Item 6 & 4.81 & 4.7 & -0.66 & 0.51 & 4.66 & 4.65 & -0.23 & 0.82 \\
\hline
\end{tabular}

${ }^{*}$ Denotes statistical significance $(\alpha=.05)$

Figures 1 and 2, shown below, display the weighted means pre-session and post-session for both groups of students. Table 5, above, shows the weighted means of each questionnaire item pre-session and post-session, as well as the t-test statistics. The item with the largest increase among PT students was item 1, or "I am comfortable working as part of a PT-PTA team." None of the items found to be significantly different after the interactive session were associated with decreases in the weighted mean, suggesting that overall impacts were positive among students.

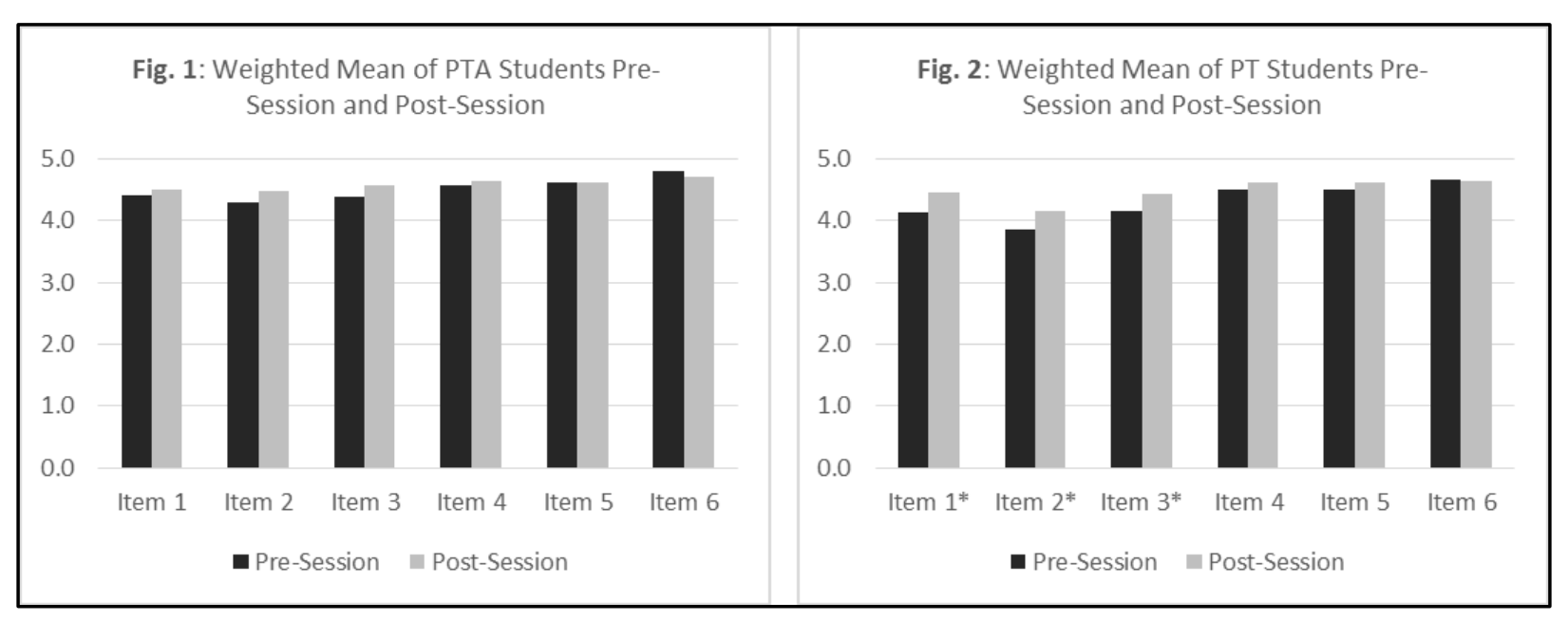

\section{DISCUSION}

In conclusion, the purpose of this study was to assess PT and PTA students' attitudes toward working in a team, direction and supervision, preparation for effective communication, respect for and the value of PT/PTA teams following an interactive classroom session via a brief online questionnaire. The results suggest that both PT and PTA students felt more positive and comfortable about their professional communication and teamwork roles and responsibilities. Outcomes were generally positive and improved 
after the interactive event, supportive of fostering the PT/PTA relationship. The findings are important in noting that both PT and PTA students reported increased comfort with the idea of working as part of a PT/PTA team after the interactive event where communication was the main focus. The affective behavior of "comfort" in working as part of a PT/PTA team increased in our study among both PTs and PTAs. Improvements in affective behaviors are noted in a number of other studies. ${ }^{1,2,6}$ In a study by Jung et.al, the significance of "communication, respect, and trust" in building the professional/assistant healthcare relationship was stressed. ${ }^{1}$ Jelley et al. reported that PT and PTA students identified communication as the essential element required for effective IPE. ${ }^{2}$ Plack et al., in a classroom based study, found "The PT students ... developed an appreciation for the skills and affective behaviors integral to the development of the effective clinical relationships of PTAs". ${ }^{6}$

The interactive session was easy to implement and had no cost associated with it. Since the conclusion of this study, this experience has expanded to include an additional area PT Program with similar outcomes in PT student pre and post survey results. Having an informal opportunity for engagement between PTs and PTAs as part of the curriculum has been well received and enjoyed by students.

These findings can be applied across healthcare professions that utilize professional and assistant relationships. Within these unique and essential healthcare relationships, communication, trust, and respect are critical to exceptional patient care and safety. As educators, the affective domain is often ignored or difficult to teach. Yet, it is this domain that makes these relationships work. Any opportunity to grow within the affective domain in healthcare education is beneficial.

\section{Limitations}

The limitations of this study include the lack of a control group as well as using a sample of convenience. There were only two cohorts from two academic programs limiting generalizability. Given the lower number of PTA students, it's possible that the differences observed in the PTA group would have been found to be significant with a larger $n$, similar to the PT student category (which had a larger $n$ ). In addition, the collection of anonymous data with limited demographic characteristics precluded a more robust repeated measures or matched pairs analysis that would directly assess changes in students.

\section{Recommendations}

Our recommendations for further study are to set up a PT/PTA clinical rotation to allow for increased interaction and collaboration. Additional study using the above described repeated measures or matched pairs analysis may be warranted in order to confirm the suggested findings from this study. Exploration as to why PTs reported being more comfortable after an interactive event, when compared to PTAs, would also be beneficial.

\section{REFERENCES:}

1. Jung B, Salvatori P, Martin A. Intraprofessional fieldwork education: Occupational therapy and occupational therapist assistant students learning together. Can J Occup Ther. 2008;1(75):42-50. [PMID: 18323368]

2. Jelley W, Larocque N, Borghese M. Perceptions on the Essential Competencies for Intraprofessional Practice. Physiother Can. 2013;65(2):148-51. [PMID: 24403676]

3. Robinson AJ, McCall M, DePalma MT, Clayton-Krasinski D, Tingley S, et al. Physical Therapists' Perceptions of the Roles of the Physical Therapist Assistant. Phys Ther. 1994;74(6):571-82. [PMID: 8197243]

4. Robinson AJ, DePalma MT, McCall M. Physical Therapist Assistants' Perceptions of the Documented Roles of the Physical Therapist Assistant. Phys Ther. 1995;75(12):1054-64. [PMID: 7501708]

5. Cavallo CL, Richter RR. Attitudes of Physical Therapist Students Toward Physical Therapist Assistants Before and After FullTime Clinical Internships. J Allied Health. 2004;33:10-6. [PMID: 15053215]

6. Plack MM, Williams S, Miller D, et al. Collaboration Between Physical Therapists and Physical Therapist Assistants: Fostering the Development of the Preferred Relationship Within a Classroom Setting. J Phys Ther Educ. 2006;20(1):3-13.

7. Mathews H, Smith S, Hussey J, Plack M. Investigation of the Preferred PT-PTA Relationship in a 2:2 Clinical Education Model. J Phys Ther Educ. 2010;24(3):50-61.

8. Shoemaker MJ, Platko CM, Cleghorn SM, Booth A. Virtual patient care: an interprofessional education approach for physician assistant, physical therapy and occupational therapy students. J Interprof Care. 2014;28(4):365-7. [PMID: 24593330]

9. Gunnell M, Madsen K, Foley L. Using simulation to implement interprofessional education. American Nurse Today. 2016; 11(11):45-6.

10. Sullivan $\mathrm{K}$, Charrette $\mathrm{A}$, Massey $\mathrm{C}$, Bartlett $\mathrm{D}$, Walker $\mathrm{C}$, et al. Interprofessional education with a community fall prevention event. J Interprof Care. 2015; 29(4):374-6. [PMID: 25317499]

11. Tervaskanto-Maentausta T, Nordstrom T, Varkki E, Taanila A. The longitudinal study of medical and health care students' experiences and attitudes towards interprofessional learning in first semester course. European Scientific Journal. 2016;12(15):23-37.

(C) The Internet Journal of Allied Health Sciences and Practice, 2018 
12. Thompson BM, Bratzler DW, Fisher MJ, Torres A, EPIC Faculty, Sparks RA. Working together: Using a unique approach to evaluate and interactive and clinic-based longitudinal interprofessional education experience with 13 professions. J Interprof Care. 2016;30(6):754-61. [PMID: 27797628]

13. SurveyMonkey website. Available at: https://www.surveymonkey.com/ Accessed September 14, 2017. 